\title{
Justiça e justiças nas democracias: perspectivas de acesso às "reqras do jogo"
}

\author{
ALEXANDER GAMBRAIA NASCIMENTO VAZ
}

\section{Resumo}

O artigo empreende um debate acerca das possibilidades de conciliação entre justiça e legitimidade nas democracias contemporâneas. Estados liberaldemocráticos tendem a ter um compromisso específico com a questão da legitimidade como forma de lidar com a pluralidade e ordenar o âmbito social, já que consensos são obtidos através de processos e ritos formais determinados. Não obstante, a legitimidade de uma decisão não prediz qualquer caráter de justiça como elemento de suas bases, atestando-se que, na verdade, o liberalismo está preocupado muito mais com a garantia da igualdade na liberdade do que com a garantia de igualdade efetiva entre os indivíduos. $\mathrm{O}$ artigo faz uma leitura da questão, através da recuperação de três macro-vertentes específicas, a saber: o liberalismo, a perspectiva deliberativa e a perspectiva da representação política.

Palavras-chave: Justiça. Legitimidade. Reconhecimento. Participação política.

\footnotetext{
*Ministério do Desenvolvimento Social e Combate à Fome (Brasil)
} 


\section{Justice and legitimacy in democracies: possibilities of access to the "rules of the game"}

\section{Abstract}

This article discusses the possibilities of reconciliation between justice and legitimacy in contemporary democracies. Liberal-democratic states tend to keep a particular commitment to the issue of legitimacy as a way of dealing with the plurality and regulating the social context, since consensus is achieved by means of particular processes and formal rites. Nevertheless, the legitimacy of a decision does not suppose to be based on any trait of justice, as in fact it is observed that the liberalism is rather concerned about the guarantee of equality in freedom than about ensuring effective equality between individuals. The article analyses the issue by revisiting three macro theoretical approaches, namely liberalism, deliberative democracy and political representation.

Keywords: Justice. Legitimacy. Recognition. Political participation.

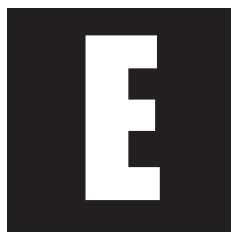

ste artigo consiste em uma exploração das potencialidades de conciliação entre justiça e legitimidade nas sociedades democráticas contemporâneas, pressupondo que são conceitos de motes e extensões diferentes e que, por isso, implicam consequências diversas para uma perspectiva de efetivação deste sistema. A estrutura política decisória dos Estados liberal-democráticos funciona sobre o pilar da legitimidade das decisões tomadas, as quais são alçadas à posição de regras sociais de "dever ser". São pelo menos duas as razões que justificam esse estado de coisas.

Em primeiro lugar, a acepção de que os indivíduos que atuam no legislativo efetivamente representam a vontade do povo. Isso implica dizer que o poder constituído se funda numa premissa básica de que as regras de "dever ser" expressam, necessariamente, um consenso coletivo sobre factu- 
almente o que "deve ser" a sociedade. Em segundo lugar, esse "dever ser" encontra respaldo numa perspectiva de legitimidade e, portanto, de vinculação ao conjunto da sociedade, porque perfeito sob ritos formais específicos. Desde que respeite determinadas regras procedimentais, um processo de formulação de regras vinculatórias adquire caráter de validade prática.

Mormente essa configuração do sistema político-decisório nacional, garantir legitimidade às decisões tomadas implica, tão somente, garantir autorização a um procedimento específico para tomar decisões, quando a unidade de opiniões, valores e preferências afigura-se inalcançável, ou pelo menos de difícil consecução. Isso quer dizer que, na verdade, não necessariamente decisões legítimas se revestem também de um caráter justo, sendo relativamente fraca, neste sentido, uma preocupação específica da democracia liberal com o elemento da justiça para além da garantia de liberdade, ou com a consecução de uma igualdade de caráter efetivo e concreto entre os indivíduos.

Existe, assim, uma dada antinomia entre justiça e legitimidade, a qual gera situações como, por exemplo, a existência de uma profunda desigualdade no tocante ao acesso à justiça pelos cidadãos - considerando que este acesso constitui prerrogativa básica de efetivação de direitos para aqueles que vivem sob regras coletivas de "dever ser". Ao passo que alguns indivíduos possuem condições financeiras para contratar advogados, por exemplo, outros dependem da oferta pública deste serviço, através das defensorias públicas, as quais, vale dizer, sequer existem em alguns lugares do país. Nesse mesmo sentido, ao passo que alguns indivíduos e grupos têm condições claras de influenciar a produção de leis no país, outros ficam excluídos e, assim, dificilmente garantem seus direitos, geralmente por possuírem menor volume ou mesmo nenhum dos recursos valorizados para tanto.

A complexidade do tema será expressa ao checarmos, por exemplo, como recentemente alguns autores já têm sugerido, aspectos dessa 
conciliação, mas, ainda assim, sem lograr respostas efetivas do ponto de vista de sua concretização. Isso se dá em função de pelo menos três elementos (Araújo, 2002).

Primeiro, a multidimensionalidade do próprio conceito de justiça, o qual busca dizer da existência de desigualdade em campos e temáticas diversas. Segundo, institucionalmente a questão da justiça nos oferece poucos subsídios consistentes para pensar como, factualmente, operacionalizar suas bases, pois é profundamente normativa e muito pouco descritiva / explicativa. Por último, face à impossibilidade de gerar um consenso coletivo "perfeito", isto é, uma situação na qual todos os indivíduos estariam pactuados sobre todos os assuntos, a questão da justiça enfrenta, ainda, o problema de ter de buscar um consenso moral sobre os tipos de desigualdades que deveriam ser aceitos.

Este texto procura condensar as respostas até então dadas a estas problemáticas numa perspectiva crítico-comparativa e não exaustiva, trazendo-se à baila a questão da justiça e a forma pela qual ela foi e tem sido estruturada por autores ligados a três macro vertentes de estudo: o liberalismo, a "democracia deliberativa" e a representação política. Pode-se dizer, desde já, que uma diferenciação básica entre tais linhas de pensamento reside na forma como tratam o elemento político em suas respectivas considerações face às proposições de validação dos preceitos de justiça. Dependendo da forma pela qual o fazem, serão mais ou menos capazes de conciliar os julgamentos de legitimidade e os julgamentos de justiça.

É a seguinte a organização do trabalho. Em primeiro lugar, a antinomia entre justiça e legitimidade é elucidada através do resgate do debate travado entre liberais no âmbito da teoria política contemporânea, especialmente nas figuras de Rawls e Dworkin. Demonstra-se como a filosofia política é reconfigurada elevando-se o tema da justiça à posição de padrão para julgamento das democracias. 
Logo após, traz-se à baila a perspectiva de autores como Michael Sandel e Habermas que, de forma crítica a tal viés, pretendem relacionar justiça e legitimidade sob uma ótica de, respectivamente, intersubjetividade e justificação pública. Em terceiro lugar, traz-se à baila a concepção de autores que já ensaiam uma perspectiva de conciliação entre justiça e legitimidade buscando base no ardiloso campo da representação política. Por fim, são tecidas as considerações finais.

\section{A justiça como padrão de julgamento e a legitimidade em segundo plano}

As primeiras assertivas acerca da questão da justiça à luz da filosofia política são encontradas na matriz do próprio liberalismo. A relação entre justiça e legitimidade foi tratada por autores dessa vertente sem a consideração e o trabalho com uma base política específica e, nesse sentido, o que se observou foi, na verdade, a concepção de conjecturas acerca da primazia da justiça através da elaboração de prospectos para sua validação.

A principal consequência da desconsideração do substrato político, assim, foi o obscurecimento dos julgamentos de legitimidade e da própria perspectiva democrática como elemento organizador das sociedades. Isso implica, vale dizer, a existência de limites claros nas obras destes autores sob o ponto de vista da concretização de normas de "dever ser" e de efetiva ordenação dos agrupamentos sociais.

Sem dúvida, o principal expoente dessa perspectiva foi John Rawls, que inverte a lógica de julgamento e padronização da filosofia política e, ao invés de levar em consideração a legitimidade como pilar básico das relações sociais, assume que a justiça deve alçar tal posição, o que ocorreria através da garantia de recursos iguais para os cidadãos numa situação em que todos a tomariam por base moral de sua ação ante valores e crenças 
particulares. A justiça é entendida, assim, como um padrão pelo qual valores e concepções conflitantes são trabalhados, isto é, "pesados", com fins de se alcançar consensos e/ou harmonizações específicas na vida social.

Nesse sentido, ela pode ser vista como um árbitro dos conflitos sociais. Não obstante, se é verdade que o liberalismo clássico não tem preocupações claras com uma forma de justiça específica que garanta igualdade para além do aspecto formal de garantia das liberdades, a análise da obra desse autor revela que as primeiras incursões no debate sobre justiça redundaram num nível de normatividade significativo do ponto de vista da reflexão sobre regras sociais.

Tal como todos os padrões de julgamento, a justiça deve, por um substrato lógico, anteceder as próprias coisas julgadas. Encontrar este ponto inicial, este Archimedian Point (AP), consiste, para Rawls, em mais do que um problema moral, constitui um problema de ordem epistemológica. Se considerarmos que a justiça é derivada dos valores e concepções de bem correntes em determinada sociedade, ela não poderia servir como padrão, pois todas suas afirmativas sofreriam contingência imediata. A primazia da justiça está ligada à afirmativa deontológica básica da primazia de princípios de direito/justiça sobre valores e desejos individuais.

Ao se filiar à perspectiva deontológica e se firmar contrário à teleologia, Rawls desenha um viés peculiar para com a personalidade individual, ou um tipo específico de sujeito moral. Seu elemento essencial, isto é, constituinte, definidor, não seriam os valores e bens alcançados, mas, sim, a capacidade de escolher e buscar estes valores e bens.

Nesse sentido, o próprio self é anterior, isto é, tem primazia sobre os seus fins e valores, o que quer dizer, em última instância, que ele não depende desses últimos para firmar seu próprio caráter e personalidade. O self, por fim, não é um mero produto das circunstâncias e da experiência acumulada, um elemento passivo e por estas definível, mas, antes, 
um sujeito definidor, ativo, capaz de perfazer escolhas específicas e independentes dos valores que o circundam. O indivíduo é, na verdade, um sujeito de posse, porque seus valores lhe pertencem e não the definem.

A partir dessa proposição epistemológica, Rawls estabelece as bases do que seria uma sociedade justa, através da adoção da ideia de posição original. Esta é pensada como uma situação na qual o senso de justiça, ou o conceito de justiça (assim como o self), é concretizado nem tão ligado aos valores correntes (o que implicaria contingência total), nem tão deles afastado (o que configuraria o ser metafísico de Kant), mas exatamente no Archimedian Point.

Para tanto, Rawls assume dois pressupostos com relação aos indivíduos, sendo que o primeiro é um dos mais famosos, relativo ao véu da ignorância. Nessa situação, os indivíduos não têm informações tais que os fariam capazes de se distinguir mutuamente para além de seu caráter fundamental como seres humanos. Eles possuem concepções gerais acerca dessas informações, mas devem, antes, primar suas ações pelos princípios de justiça.

Por outro lado, os indivíduos sabem que determinados bens são mais valorizados do que outros, porque sua consecução é capaz de aumentar as chances de que seus outros bens sejam maximizados, sejam quais forem estes últimos. Esses bens de consideração inicial são os chamados bens sociais primários. Na posição original, Rawls assume que os indivíduos são motivados pela concretização destes bens sociais primários.

Essa é a teoria escassa do bem e ela é escassa porque assume poucos pressupostos, mas que são amplamente compartilhados, úteis para se atingir qualquer concepção outra e mais específica/particular de bem num momento posterior. A motivação da posição original, portanto, reside justamente em se chegar a um consenso acerca de concepções específicas que, num momento posterior, permitirão a todos a maximização do seu bem-estar. 
A partir dessas duas proposições, Rawls deriva dois princípios de justiça: o primeiro, referente à garantia da igualdade na liberdade para todos os indivíduos. Naturalmente, espera-se do autor tal posicionamento, dado que filiado à escola liberal. Não obstante, sua segunda assertiva é aquela que o diferenciou em maior medida dos seus pares: as desigualdades econômicas e sociais devem ser ordenadas de tal modo que, ao mesmo tempo (a) tragam o maior benefício possível para os menos favorecidos, obedecendo às restrições do princípio da poupança justa, e (b) sejam vinculadas a cargos e posições abertos a todos em condições de igualdade de oportunidades.

Através da consideração de um sujeito moral tal como o desenhado, que prima a justiça em relação a seus próprios valores, Rawls afirma que os dois princípios de justiça colocados seriam suficientes para garantir justiça social. Até mesmo as características intrínsecas dos indivíduos, como inteligência, ambiente familiar, deveriam ser igualadas por instituições criadas sob a égide dos princípios de justiça, pressupondo, nessa linha, que ninguém, na verdade, teria um valor moral intrínseco.

Ao alçar a justiça como padrão básico para resolução de conflitos sociais, ante o conceito de legitimidade, Rawls certamente dá um passo ao mesmo tempo inovador, mas arriscado. De fato, há que se reconhecer que uma sociedade tal como a postulada pelo autor sequer necessitaria de políticas específicas para promoção de justiça, a não ser aquelas para criação de instituições que igualassem as características intrínsecas dos indivíduos, porque a justiça seria automaticamente primária a qualquer outra política e sempre de forma perfeita, balanceada e não enviesada, dado que valores e crenças não seriam variáveis sequer intervenientes. O que importaria, na verdade, seria a validade dos princípios de justiça elencados e não a sua legitimidade. 
Não obstante, há limites claros em seu pensamento sob o viés de concretização dessa perspectiva. Em primeiro lugar, vale enfatizar a abstração do pensamento. O próprio autor, respondendo a algumas críticas nesse sentido, já declarou que a ideia da posição original não está factualmente sujeita a qualquer teste sociológico.

Imaginar uma posição inicial da sociedade é o mesmo que se referir, como base substancial, aos chamados mitos fundadores, os quais, por suas próprias características, recebem a denominação de mitos. Em segundo lugar, neste mesmo sentido, vale questionar as bases do sujeito moral do autor, as quais são, ao mesmo tempo, infactíveis e rígidas.

Infactíveis, porque Rawls considera a possibilidade de os sujeitos não se relacionarem com o mundo através de seus valores. Por si só, esta já consiste em uma afirmativa deveras difícil de considerar - sujeitos que não se guiam por valores e crenças - o que implicaria simplesmente desprezar, por exemplo, toda a história do cristianismo e outras religiões e suas respectivas influências na formação das sociedades. Além disso, por causa dessa rigidez, o sujeito moral de Rawls tende a ser transcendental, isto é, não passível de transformações.

O movimento iniciado por Rawls acerca da primazia da justiça como padrão de julgamento para organização e garantia de segurança às relações sociais teve impactos e ressonâncias por toda a filosofia política contemporânea. Outro importante autor que lidou com a temática foi Ronald Dworkin. Crítico a Rawls, esse autor postulou a ideia de que à questão da justiça deveria corresponder, necessariamente, uma teoria do direito, isto é, uma teoria de positivação de normas como forma de factualmente a concretizar e servir de aporte. Dworkin é um dos primeiros autores dessa linha que concebem um papel significativo e de certo contraditório ao Estado, como agente capaz de garantir a justiça e não como um ator do qual os cidadãos deveriam se proteger constantemente. 
A primeira crítica que o autor tece a Rawls refere-se ao ordenamento dos princípios de justiça, especificamente de que o princípio de garantia de liberdade não bastaria para garantir a concretização do segundo princípio, referente ao tratamento das desigualdades sociais. A concepção de Rawls acerca do caráter dos indivíduos, ao considerar que seriam, na verdade, sujeitos de posse, isto é, indivíduos cujo caráter não seria definido pelos valores e crenças, mas, sim, capazes de escolher valores e crenças que melhor the aprouvessem, indicaria seu conservadorismo em relação aos padrões morais do liberalismo.

A essa noção de posse estaria circunscrita uma premissa de capacidade de escolha e de definição pragmática de meios e fins objetivando a maximização do bem-estar própria do liberalismo clássico. E essa base de julgamento não seria o suficiente para garantir a igualdade necessária à concretização do segundo princípio de justiça, porque nada garantiria que, mesmo nas condições do véu da ignorância, os indivíduos não viessem a escolher princípios de justiça tais que julgassem lhes colocar em melhor posição do que os demais, buscando maximizar suas respectivas posição e bem-estar relativos.

Dessa crítica inicial ao trabalho de Rawls, é que Dworkin é capaz de elaborar as bases de sua teoria da justiça alicerçada na necessidade de garantia de igualdade como um primeiro princípio de justiça, ante a ideia de liberdade defendida por Rawls. De fato, Dworkin acredita que somente garantindo a existência de igualdade como ponto inicial básico, entendida como respeito e considerações mútuas, é que se tornaria possível lidar de maneira eficiente e efetiva com as desigualdades sociais.

A seu turno, a garantia dessa igualdade restaria dependente de uma teoria do direito para se concretizar, isto é, da positivação de normas sociais capazes de tornar um "dever ser" as condições de igual consideração e respeito pelo outro. Daí é derivada a importância do Estado como 
agente capaz de efetivar essa normatização e prever sanções específicas para o seu descumprimento.

Em momento algum, Dworkin está preocupado com uma perspectiva de neutralidade moral, isto é, com a presença e/ou mesmo necessidade de um consenso coletivo acerca de determinados preceitos que deveriam ser normatizados. Ao contrário da ideia de legitimidade, essa neutralidade moral afigura-se redundante em relação à garantia de igualdade e poderia eventualmente ser trazida à baila apenas em função de uma necessidade específica e circunstancial de efetivação da própria igualdade.

Percebe-se, nessa linha, que a igualdade deve ser considerada, na verdade, sempre na dimensão do indivíduo e não numa dimensão grupal qualquer, e que, ademais, toda a aprovação de regras de "dever ser" está ligada à garantia de que os indivíduos sejam dados como iguais.

Nessa linha, o Direito pode ser entendido muito mais como uma série de prerrogativas e "armas" disponíveis aos indivíduos para garantia dessa igualdade do que como um sistema fim cuja existência seria justificada para organizar as relações sociais e estruturar a sociedade como um todo. Ele consiste muito mais, assim, numa série de direitos morais e políticos, alçados à posição de direito positivado, cujo reconhecimento deve ser imediato e impositivo, tão logo exigido por qualquer indivíduo recorrendo às instâncias adequadas, as quais, no caso, consistem nos tribunais, ou no poder judiciário. E, nesse caso, resta significativo o papel desempenhado pelos juízes na dinâmica social como um todo.

De fato, os tribunais tornam-se a instância decisória por excelência e os juízes adquirem papel central, principalmente na formulação de novos direitos. Dworkin confere um enfoque principiológico significativo à sua teoria da justiça, afirmando que o Direito não resulta num simples emaranhado de regras rígidas, ou, ainda, num compêndio de autoridades e seus respectivos poderes, mas, antes, numa ação de cunho interpretativo e de autorreflexão, capaz de evoluir em função das mudanças de caráter social. 
Nessa perspectiva, a questão da justiça é tomada como uma série de direitos individuais, cuja origem não pode ser determinada nem pela ideia de bem comum, nem por sua concepção subjacente, referente a um padrão social construtivista, cujo resultado final afigura uma dialética de valores e crenças minimamente acordados entre os indivíduos. A ideia de neutralidade moral reside muito mais no ordenamento dos princípios do que num consenso moral perfeito através de regras de legitimidade. E o "porta-voz" dessa integridade moral é justamente o juiz:

[...] Quando um juiz declara que um determinado princípio está imbuído no direito, sua opinião não reflete uma afirmação ingênua sobre os motivos dos estadistas do passado, uma afirmação que um bom cínico poderia refutar facilmente, mas sim uma proposta interpretativa: o princípio se ajusta a alguma parte complexa da prática jurídica e a justifica; oferece uma maneira atraente de ver, na estrutura dessa prática, a coerência de princípio que a integridade requer. O otimismo do direito é, nesse sentido, conceitual; as declarações do direito são permanentemente construtivas, em virtude de sua própria natureza (Dworkin, 2007, p.25).

O Estado, na perspectiva do autor, tem por pilar uma função primordial do direito, o que não quer dizer, a seu turno, qualquer coisa acerca da democracia. Pelo contrário, ao atribuir aos juízes o papel de compiladores de direito, Dworkin prevê que eles decidam politicamente, o que contraria um princípio básico da democracia de que as decisões políticas e as decisões jurídicas teriam natureza diferente. Sob esse argumento, os juízes não teriam legitimidade para decidir o moralmente correto ou incorreto, porque essa tarefa estaria a cargo da democracia representativa e suas respectivas regras de legitimidade, as quais, na verdade, deveriam ser reforçadas.

O papel dos juízes seria justamente alavancar esse reforço através de decisões que não fossem contrárias aos pontos acordados, mas, antes, que neles se embasassem. Dworkin, não obstante, está preocupado muito mais com a validade das decisões tomadas pelo judiciário do que com 
a sua legitimidade e, por isso, presume poder aos juízes tal qual aquele predito aos legisladores.

Elevar a questão da justiça ao patamar de elemento primário organizador da sociedade é, ao mesmo tempo, a base das teorias de Rawls e Dworkin, mas implica, para ambos, consequências comuns e específicas. Em primeiro lugar, para os dois casos observa-se que o elemento político, relacionado ao conflito e à disputa, é deixado de lado. Os padrões de julgamento são decididos de maneira assertiva sem qualquer recurso ao conceito de legitimidade, primando, basicamente, por sua validade.

Isso nos leva ao segundo ponto, que é, por consequência, a não exigência de um consenso ou neutralidade moral para positivação e efetivação de normas de "dever ser". A democracia é relegada a segundo plano em ambas as teorias, e a estrutura analítica montada se caracteriza por uma abstração e uma formalidade significativas do ponto de vista da organização social.

Nesse sentido, a relação entre justiça e legitimidade adquire um viés claro de favorecimento da perspectiva da justiça, pretendendo a resolução, dessa forma, dos conflitos advindos dessa interação. Analiticamente, não obstante, essa solução não implica equilíbrio entre ambas as esferas e, por isso, se, no caso do liberalismo clássico, observava-se a primazia dos preceitos da legitimidade como causadora de imprecisão e geradora da problemática que embasa a discussão, nesse caso observa-se exatamente a mesma coisa, ainda que pelo caminho inverso.

A problemática clara que resta a partir dessas considerações consiste em saber como estruturar uma base teórico-analítica que consiga operar a primazia da justiça num contexto cujos pilares estejam assentados na geração de normas de "dever ser", a partir da obtenção de um consenso moral coletivo. 


\section{Buscando preceitos de justiça e legitimidade}

Pode-se dizer que uma aproximação significativa a tal problemática é empreendida no momento em que o liberalismo de Rawls e Dworkin encontra significativa resistência dentro da própria matriz liberal, bem como através de teóricos da democracia. A principal crítica adveio da falta de um elemento político, em suas respectivas teorias, que servisse como ponto de interveniência entre julgamentos de justiça e julgamentos de legitimidade. A falta deste substrato implicaria um distanciamento em relação à realidade capaz de inutilizar qualquer concepção de concretização de justiça no âmbito social.

A conexão entre ambos os elementos estaria relacionada muito mais a um substrato político específico capaz de agregar, ao mesmo tempo, uma perspectiva de bem comum - isto é, uma ótica de validação dos preceitos de justiça - e uma base de legitimidade cuja natureza não necessariamente estaria ligada a regras e/ou a formalidades específicas.

Do lado do liberalismo, os comunitaristas propuseram uma justificativa para a validação dos princípios de justiça que buscou se embasar num tipo de legitimidade advinda da partilha de valores e crenças sociais. Trabalhando nessa vertente, Sandel (1992a), por exemplo, estabelece uma concepção de criação de princípios morais recorrendo aos valores e crenças coletivas / comunitárias.

Estes valores e crenças, na verdade, seriam o mote principal de qualquer empreitada para se alcançar justiça, o que se daria através da existência de padrões de relacionamento entre os indivíduos que, em função de processos dialéticos e intersubjetivos, alcançariam consensos específicos quanto ao conceito de justiça. Toda a base da teoria comunitarista consiste na existência desses tipos de processos com foco num paradigma de ação de cunho comunicativo, isto é, de que os indivíduos não são 
entes cujos interesses e preferências são construídos previamente às interações, mas, antes, que estes são construídos através desses processos.

Ao discutir a ideia de coesão social, Rawls faz uma distinção entre dois tipos de sociedade. Em primeiro lugar, aquela de cunho instrumental, na qual a cooperação ocorre com fins de que os sujeitos, cada qual, possam, a partir de sua efetivação, buscar a maximização do bem-estar individual. É uma concepção egoística por excelência, a concepção instrumental. Desse viés, Rawls elabora a sua ideia de comunidade, que é a aquela na qual os indivíduos compartilham de determinados fins (os princípios de justiça e a teoria escassa do bem) e a cooperação é um bem, não um simples meio.

Esta é a concepção sentimental. No primeiro caso, a ideia de comunidade é completamente externa ao indivíduo e, no segundo, ela é parcialmente interna (valorada em algum sentido). Ambas, no entanto, não conseguem lidar com o problema de que os valores morais dos indivíduos são delegados à coletividade numa perspectiva instrumental. Isto é, se o indivíduo nasce com um nível maior de inteligência (e, por isso, mais propenso a atingir níveis melhores de bem-estar e condições de vida), ele próprio não pode, segundo as disposições de Rawls, utilizar esse atributo em proveito próprio, mas deve, obrigatoriamente, fazê-lo com vistas a prezar o bem da coletividade, em função de algum proveito para a coletividade.

Lidar com esta questão requer uma concepção mais aprofundada, ou ampliada, de comunidade, que atribua à cooperação muito mais do que um sentido de bem, muito mais do que um sentimento de pertencimento, mas a reconheça numa perspectiva de constituição identitária do indivíduo. Nessa linha, a identidade dos indivíduos é construída pela sociedade, sendo que esta não é um bem possuído, mas os sujeitos são a própria comunidade. Esta é a concepção constitutiva. 
A concepção constitutiva está embasada numa ampliação da ideia do sujeito de posse. Este passa a ser entendido como aquele capaz de participar da constituição de sua identidade, através de uma capacidade de empreender reflexão e autoconhecimento chamada agency. A ideia de intersubjetividade de Sandel basicamente coaduna com as bases da concepção constitutiva e, de fato, consegue expor uma justificativa consistente para a ideia de justiça de Rawls, ao lidar com o indivíduo e sua preocupação com a sociedade, não porque possui um senso de justiça prévio, que antecede seus próprios valores, mas, antes, porque se identifica com os valores e crenças dessa sociedade.

Os comunitaristas se diferenciam de Rawls e Dworkin ao conferirem outro tipo de justificativa à primazia da justiça, que não aquela baseada ora em sujeitos morais possuidores de valores, ora na figura dos juízes e do judiciário. Eles estão claramente preocupados em estabelecer uma justificativa de bem comum cuja base tenha características eminentemente comunitárias, coletivas e que seja, com isso, capaz de explicar a coesão e os processos sociais como um todo.

Assim, sua proposta de conciliação entre legitimidade e justiça advém da reconfiguração do conceito de legitimidade, passando-o de um instrumento objetivo para resolução de conflitos, para um elemento resultante da mútua constituição identitária, capaz de potencializar a ação coletiva, coesa e organizada em torno e em prol de temáticas tais como a justiça.

A obra de Sandel avança, assim, ao propor uma aproximação entre julgamentos de justiça e julgamentos de legitimidade, sugerindo a justificativa de um bem comum advindo da partilha de valores e crenças pelos indivíduos e não como resultante de formalidades e ritos específicos. Sua atenção está voltada, portanto, para a validade dos preceitos de justiça, mas ainda não encontramos, em seus escritos, pistas concretas sobre a operacionalização desse processo. Isso quer dizer que, na verdade, embora se dife- 
rencie dos liberais, um substrato político específico ainda não foi passível de inserção pelo autor nas suas considerações sobre a questão da justiça.

Trabalhando nessa linha, Habermas elaborou uma proposta de conciliação entre justiça e legitimidade, com base num elemento político que, ao mesmo tempo, combina elementos procedimentais e elementos de cunho intersubjetivo afins àqueles da concepção constitutiva da escola comunitarista. O autor trabalha uma concepção de procedimentos que visam o estabelecimento de relações intersubjetivas para o alcance de consenso entre os indivíduos através da argumentação e da persuasão numa situação ideal de fala. Processo que, não obstante, ainda trata como substratos diferenciados e, portanto, separados, os julgamentos de legitimidade e os julgamentos de justiça.

O autor parte de um modelo de ação que concebe o poder numa dimensão coletiva - e não individual. A capacidade de gerar consenso é contraposta à ideia de violência na medida em que o próprio tipo de ação em que se baseiam cada uma dessas categorias é diferente. No primeiro caso, a ação é orientada para o entendimento recíproco, para o consenso em torno de temáticas específicas; no segundo caso, o agir é a ação voltada para a maximização do bem-estar individual.

O poder em Habermas está alicerçado muito menos, assim, na ação instrumental, no agir pragmático, mas, antes, tem por pilar o agir comunicativo, o "estabelecimento não coercitivo de relações intersubjetivas", isto é, uma vinculação entre os indivíduos calcada em relações elocutórias e não assimétricas.

O debate, a deliberação em torno de temáticas específicas seria fundamental para o alcance de consensos acerca de questões coletivas, através da livre argumentação, confrontação/validação de preferências diferenciadas e persuasão em fóruns públicos e abertos (Habermas, 1980; 2003). Discussões extraparlamentares, caracterizadas como temáticas e 
assuntos diversos tratados nos espaços públicos, ou em espaços institucionalizados de interação face a face (Avritzer, 2002), deveriam ser levadas em consideração pelos legisladores, quando de sua tomada de decisão (no tocante à produção de leis e/ou normativas sociais), com o risco de incorrerem no chamado gap de legitimidade (Habermas, 2003).

Enfatiza-se, nessa linha, o elemento participativo como procedimento social a ser empreendido no sentido de influenciar e/ou mesmo informar as deliberações e tomadas de decisão dos representantes eleitos (Avritzer; Costa, 2004). Tal perspectiva está ancorada na relação entre a concepção de espaço público e a própria concepção de democracia, que resulta num importante princípio teórico: a legitimidade de uma decisão está relacionada à participação e possibilidades de influência daqueles potencialmente afetados por ela nos processos deliberativos que as levou a serem tomadas (Santos; Avritzer, 2003).

A preocupação de Habermas, nota-se, consiste em estabelecer uma conciliação entre justiça e legitimidade, que esteja ancorada num consenso moral coletivo obtido através de um procedimento de cunho deliberativo empreendido entre os cidadãos. Existe, portanto, uma expressão clara de um elemento político na teoria do autor que pretende agir como aglutinador dessas duas perspectivas e que se ancora na perspectiva daquele indivíduo e/ou grupo social com maior capacidade de argumentar e persuadir. Não obstante, pelo menos três características da teoria de Habermas implicam uma persistente disjunção entre julgamentos de justiça e julgamentos de legitimidade, que o levam a recair em limites específicos quanto aos objetivos de tentar conciliar estes dois elementos.

Em primeiro lugar, o autor atesta sua proximidade a uma perspectiva constitucional de realização da justiça, ao lidar com um fluxo de deliberações públicas cujo fim consiste em influenciar o sistema político gerador de normas de "dever ser". Isso quer dizer que a efetivação da justiça é 
considerada função e/ou dependente das possibilidades de positivação das concepções morais - sejam quais forem - que lhes conferem embasamento. Isso nos leva ao segundo ponto, que é justamente o fato de que, a esta necessidade de positivação do consenso moral, deve corresponder justamente isso: um consenso moral único e específico.

Ainda que possa variar em conteúdo, em função do tempo e das deliberações empreendidas no espaço público, a normatização constitucional, isto é, a atribuição de caráter de "dever ser" a determinadas concepções morais, torna mandatória a univocidade dessas concepções, tornando-as vinculatórias, ainda que não necessariamente justas, pelo tempo que forem subentendidas como um consenso coletivo válido. Em terceiro lugar, com base em tudo isso, a teoria de Habermas não consegue garantir a efetivação de justiça social, porque o consenso moral tende a ficar restrito àquele indivíduo e/ou grupo com maiores capacidades de argumentação e persuasão. Nesse sentido, a positivação tende a privilegiar justamente aquelas concepções ditas dominantes em função de tais capacidades, diminuindo significativamente a participação e/ou contribuição de concepções contra majoritárias (Bohman, 2003).

Tentar trazer à tona uma conciliação entre justiça e legitimidade recorrendo a uma concepção moral coletiva implica uma diferenciação clara em relação aos liberais que trataram da temática da justiça. Em ambos os autores vistos, esse consenso moral é obtido através do estabelecimento de relações intersubjetivas e da prática de partilha e troca de crenças e valores. Há, portanto, uma reconfiguração clara do conceito de legitimidade que passa a ser entendido muito mais numa matriz axiológica, do que numa matriz de viés instrumental.

Não obstante, essa exigência de um consenso moral torna-se, ao mesmo tempo, um limitador significativo dos potenciais de realização de justiça, porque implica a presença unívoca de determinadas concepções 
valorativas como óbice desse processo. O sistema político, nessa linha, tende a comportar somente um tipo de fluxo e, portanto, considera o âmbito social como um elemento capaz gerar um tipo de consenso por vez.

A inserção de um elemento político como variável conciliadora dos prospectos de justiça e legitimidade deve levar em consideração, assim, uma perspectiva não unívoca, isto é, um viés capaz de congregar, ao mesmo tempo, uma multidimensionalidade de preceitos de justiça na forma de consensos morais. Isso quer dizer que o sistema político deve ser capaz de comportar, ao mesmo tempo, fluxos diversificados de naturezas não necessariamente coincidentes, ou, em outras palavras, consensos morais que se perfazem em arenas diferenciadas e mesmo divergentes, mas que eventualmente urgem normatização em momentos que podem ser coincidentes.

\section{Perspectivas de conciliação: a representação política em perspectiva}

O tratamento do substrato político como elemento capaz de conciliar julgamentos de justiça e legitimidade pode requerer, assim, uma ampliação da própria noção de justiça e legitimidade. A validade da justiça deve estar ligada muito mais a uma perspectiva ampla de legitimidade, a qual consiga congregar, ao mesmo tempo, concepções, valores e crenças diversas, que podem se formar e se localizar em arenas diferenciadas e mesmo antagônicas, e que, por fim, não necessariamente participem ativamente da vida política. O conceito de representação política pode ser um elemento significativo neste sentido.

Urbinati (2006), por exemplo, investiga as condições que tornam a representação democrática um modo de participação política capaz de ativar uma variedade de formas de controle e supervisão pelos cidadãos. O argumento base da autora é de que a democracia representativa é 
uma forma de governo que não é idêntica à democracia eleitoral. Seria uma forma original de governo, nesse sentido. Se a democracia eleitoral consiste num processo calcado basicamente na escolha, autorização e legitimação de representantes no ato de votar, a democracia representativa, segundo a autora, é fundada numa perspectiva de maior inclusão na produção das leis do que o referido ato.

A política, nesta linha, se faria não apenas pelo consentimento eleitoral. Consistiria, na verdade, numa dinâmica de argumentação, contra argumentação, persuasão e debate, numa "arena de opiniões contestáveis e decisões sujeitas à revisão a qualquer tempo". Pode-se dizer que a própria legitimidade dos representantes para tomada de decisão é contestada a todo instante, em uma "tarefa contínua e regulada" de processá-la. [...] continuidade para além do período eleitoral é a norma que esperamos que os representantes sigam, de forma que possamos reconhecê-los, por assim dizer, ou julgá-los sempre, não somente ao final de seus mandatos eleitorais (Urbinati, 2006, p.208).

Além de Urbinati, Young (2000) trabalha também nesse viés, ao tentar empreender uma conciliação entre justiça e legitimidade através do recurso à representação política. A autora lida com a sub-representação de grupos sociais específicos nos processos de tomada de decisões vinculatórias, especialmente acerca da marginalização destes grupos e indivíduos, ou, em outras palavras, da sua não inclusão sociopolítica.

Essa exclusão da participação nos processos de definição de regras de "dever ser" levaria a que alguns indivíduos reivindicassem propostas específicas de inclusão desses sujeitos, por meio da reclamação de sua representação, isto é, tentando afirmar seu papel como seus respectivos representantes, atuando, para isso, em torno de temáticas específicas.

A maioria dessas propostas, no entanto, recairia no equívoco de interpretar a representação como um processo de substituição, especialmente, 
para isso, recorrendo a discursos sobre identidade. Young afirma que recorrer ao debate sobre identidade implicaria recair num paradoxo, que é o de que a representação seria, ao mesmo tempo, necessária, mas impossível.

Esta impossibilidade adviria do fato de que um representante teria que interpretar a vontade de todo o povo para "agir em seu lugar", substituindo-o. Além disso, questões identitárias implicariam uma brusca redução do próprio escopo da representação, deixando de levar em consideração os vários aspectos e experiências de vida de determinado indivíduo. O fato de ser negra, por exemplo, não implicaria que apenas uma representação identitária do caráter "cor" bastaria para determinada pessoa se sentir incluída, uma vez que, por exemplo, ela poderia acumular substratos adscritivos específicos, como ser negra, mulher e muçulmana ao mesmo tempo. Neste sentido, Young atribui à representação um caráter multifacetado não calcado numa perspectiva de substituição, mas, antes, numa perspectiva de diferença.

Interpretar a representação como uma relação de diferença leva o debate, segundo a autora, para a interpretação da representação como um processo estendido no espaço e no tempo. Este processo se consubstanciaria no contato entre os entes da relação, especificamente no grau em que este encontro se daria no espaço e no tempo. Nas palavras da autora:

Em vez de interpretar o significado normativo da representação como o ato de propriamente pôr-se pelos eleitores, devemos avaliar o processo de representação de acordo com o caráter de relacionamento entre representantes e os eleitores. O representante inevitavelmente irá se afastar dos eleitores, mas também deve estar de alguma forma conectado a eles, assim como os eleitores devem estar conectados entre si. Os sistemas de representação, por vezes, deixam de ser suficientemente democráticos não porque os representantes deixam de se pôr pela vontade dos eleitores, mas porque perderam a conexão com eles. Nas democracias de massa modernas, as relações entre representantes e elei- 
tores de fato se rompem facilmente: o difícil é mantê-las (Young, 2000, p.150).

Pressupondo que a representação é, na verdade, multifacetada, o que a autora propõe, assim, é que, na verdade, a inclusão de grupos marginalizados é passível de ser concretizada entendendo-se estes grupos como conjuntos de indivíduos que comungam de determinados posicionamentos e perspectivas sociais ${ }^{1}$ (Young, 2006), ainda que sem excluir a possibilidade de que as pessoas sejam representadas em seus interesses e opiniões específicas. A Representação de Perspectivas Sociais consubstancia, assim, a possibilidade de que diversos indivíduos sejam representados numa perspectiva grupal, mas sem perder de vista os aspectos de vida de cada um, ou, dito de outra forma, a individualidade de cada qual.

De fato, tanto Young quanto Urbinati fazem uma alusão significativa à temática da representação política como elemento político propiciador de conciliação entre julgamentos de justiça e julgamentos de legitimidade. A legitimidade advém do entendimento da representação muito mais como um processo do que como um momento específico. A seu turno, a justiça advém da extensão e manutenção desse processo no espaço-tempo.

Especialmente na obra de Young, porque mais focada na exclusão de grupos e indivíduos dos processos de tomada de decisões vinculatórias, encontramos um elemento importante do ponto de vista dessa conciliação, que é aquele concernente à proposta de perspectivas sociais. Através dela, a autora é capaz de lidar com a multidimensionalidade do próprio termo justiça sem abandonar uma concepção que lhe implique, ao mesmo tempo, validade e um caráter político.

\footnotetext{
${ }^{1}$ Segundo a autora, "a perspectiva social é o ponto de vista que os membros de um grupo mantêm sobre os processos sociais em função das posições que neles ocupam." (Young, 2006:164).
} 
Ambas as autoras, no entanto, ainda encontram limites significativos em suas respectivas obras. Se é verdade que Young, por exemplo, consegue avançar no tocante a uma teoria da justiça, por outro lado pode-se observar que ela ainda fica atrelada a um prospecto de abstração tal como os outros autores vistos. De fato, considerar a representação como elemento de consecução de direitos e bens constitui um avanço sociológico relevante, mas, ainda assim, a autora não deixa claro "como" o contato entre os indivíduos seria realizado na concretização da ideia de perspectivas sociais.

Qual o tipo de ação necessária? Seriam movimentos, passeatas, entidades, organizações? O governo estaria envolvido? Qual o financiamento para isso? Enfim, qual a forma de organização factual da noção de perspectiva social? A leitura da obra de Young não permite responder a tais questionamentos de maneira direta, assim como a obra de Urbinati também não deixa clara a operacionalização de suas proposições para além dos mecanismos tradicionais de intermediação entre indivíduos e Estado, como os partidos políticos.

Algumas propostas neste sentido podem ser recuperadas, tal como a ideia de Dryzek e Niemeyer (2006), os quais tecem algumas considerações sobre a questão diferenciando a representação de pessoas e interesses específicos da representação de discursos. Assim como o faz Urbinati e Young, os autores tentam demonstrar que, na verdade, a democracia eleitoral, ainda que estendido o sufrágio ao conjunto da sociedade, não seria capaz de abarcar todas as múltiplas dimensões da política moderna. Esta última se caracterizaria pela emergência de uma multiplicidade de discursos que em pouca medida estariam sendo canalizados de facto pela via eleitoral.

Os autores sugerem, então, a criação de uma Câmara de Discursos que funcionaria a) como canalizador destes tipos de demandas e b) estaria permanentemente ligada às instâncias deliberativas. Em relação a Urbina- 
ti, pode-se dizer que esta proposta não se prende aos mecanismos tradicionais de intermediação entre indivíduos e Estado, como os partidos, tal qual sugerido pela autora. No entanto, ela tem também suas limitações. A principal se refere ao fato de que a própria criação de uma Câmara de Discursos parece um exagero teórico-analítico, algo deveras difícil de ser perfeito, na medida em que sugere a separação entre representação de indivíduos e representação de ideias. Além disso, ignora-se o fato de que não só discursos podem ser (e efetivamente são) representados, mas, também, ideias, valores e, claro, interesses diversos (Avritzer, 2007).

O recurso à noção de representação política, assim, pode ser uma saída significativa de conciliação dos julgamentos de justiça e julgamentos de legitimidade através de um entreposto político. Não obstante, há, ainda, avanços a serem dados com relação, principalmente, aos três pontos referidos no início desta seção, especialmente sob a ótica de efetiva operacionalização das propostas de sua conexão.

\section{Considerações finais}

É possível, afinal, estabelecer uma conexão consistente entre julgamentos de justiça e julgamentos de legitimidade? As respostas elencadas neste trabalho sugerem que, embora possível, essa ligação prima-se por uma complexidade significativa do ponto de vista analítico. Fato é que todas as perspectivas recaíram em limitações claras, ora em prol dos substratos de justiça, ora em prol dos substratos de legitimidade, sendo, neste último caso, através da recuperação do elemento político.

Mas, ainda assim, é possível extrair alguns elementos e lições valiosas de suas bases, através de pistas significativas que elas nos fornecem para pensar um projeto de conciliação entre questões de justiça e de legitimidade. Pode-se dizer que são pelo menos três os elementos a levar em consideração como fatores potencializadores de sucesso neste processo. 
Em primeiro lugar, é necessária a presença de um elemento político capaz de operacionalizar a aproximação entre ambos os elementos. A desconsideração do elemento da legitimidade leva a uma perspectiva de abstração com relação ao pluralismo e à diversidade de opiniões e preferências dispostas no âmbito social. Isso quer dizer que o elemento político pode garantir a consideração não somente de prospectos de validação da justiça, mas, também, de elementos que impliquem legitimidade desses prospectos.

Em segundo lugar, é preciso apreciar a necessidade de uma perspectiva constitucional, a qual atue como garantidora da efetivação de regras morais, mas desde que ponderada, ao mesmo tempo, pela concepção de um consenso moral não alicerçado num pilar de univocidade. O sistema político, centro gerador das regras vinculatórias de "dever ser", factualmente é capaz de gerar instruções claras com relação a direitos para indivíduos e/ou grupos específicos. Não obstante, tanto os canais que pretendem lhe causar influência quanto os fluxos que "transportam" essa influência podem ter origens e naturezas diversificadas no âmbito social. Nesse sentido, deve-se trabalhar com a hipótese de que não existe um único consenso moral, mas consensos morais que são passíveis de normatização na seara constitucional.

Por último, é difícil presumir tanto que os indivíduos tomarão parte dos processos definidores destes consensos morais quanto que aqueles que o fizerem terão efetivamente a capacidade de influenciar dadas definições. Existem custos associados a estas atividades, tais como tempo, renda, educação, dentre outros, com os quais nem todos têm capacidade de lidar. Não obstante, as decisões finais sobre qualquer temática terão caráter vinculatório para o conjunto da sociedade e, por isso, todos serão diretamente impactados por seus efeitos. Isso quer dizer que o elemento político deve levar em consideração uma perspectiva de geração de legitimidade conciliada a uma concepção de justiça cuja base congregue, 
dentre outros fatores, preferências e valores de indivíduos que não necessariamente estejam na esfera pública.

Uma teoria da justiça que se pretenda levar a cabo em contextos sociopolíticos específicos, marcados pelo pluralismo e por regras democráticas, deve ser capaz de combinar esses três elementos de maneira equilibrada e consistente. O que urge, assim, é principalmente uma perspectiva assentada nas chamadas "regras do jogo" democrático, a qual seja factível e concretizável no plano das sociedades, segundo tais substratos.

O recurso à representação política pode significar um potencializador efetivo da relação entre justiça e legitimidade em contextos marcados pela diversidade de valores, crenças e preferências, especialmente em função de não exigir a participação direta e ativa dos indivíduos para efetivação da ação, assim como para a construção de legitimidade.

Não obstante, vale dizer, mesmo neste caso, existem limites claros, sendo que o principal deles recai em congregar julgamentos de justiça e de legitimidade sob uma ótica que seja ao mesmo tempo factível, isto é, concretizável no plano das ações e que seja consistente com uma concepção de validação da justiça, ou, em outras palavras, capaz de efetivamente captar e lidar com os sentidos da moralidade presente nos diversos grupos e indivíduos.

Alexander Cambraia Nascimento Vaz - Doutorando e Mestre em Ciência Política (UFMG). Coordenador-Geral de Monitoramento da Demanda do Departamento de Monitoramento da Secretaria de Avaliação e Gestão da Informação / Ministério do Desenvolvimento Social e Combate à Fome (DM/SAGI/MDS). $>$ cambraia04@gmail.com

\section{Referências}

1. AVRITZER, L.; NAVARRO, Z. (Orgs.). A inovação democrática no Brasil. 1. ed. São Paulo: Editora Cortez, 2003. 
2. AVRITZER, L.; COSTA, S. Teoria Crítica, Democracia eEsfera Pública:Concepções e Usos na América Latina. Dados, Rio de Janeiro, v. 47, n. 4, p.703-728, 2004.

3. COELHO, V.; NOBRE, M. Participação e Deliberação: Teoria Democrática e Experiências Institucionais no Brasil Contemporâneo [Participation and deliberation: democratic theory and institutional experiences in contemporary Brazil], São Paulo: Letras, 2004.

4. DAGNINO, E. Sociedade civil e espaços públicos no Brasil. In: DAGNINO, E. (Org.). Sociedade civil e espaços públicos no Brasil. São Paulo,Paz e Terra, 2002. p. 9-15.

5. DAGNINO, E.; TATAGIBA, L. (Orgs.). Democracia, sociedade civil e participação. 1. ed. Chapecó: Argos, 2007. 590 p

6. DWORKIN, R. Levando os direitos a sério. São Paulo: Martins Fontes, 2002.

7. DWORKIN, R. Não existe mesmo nenhuma resposta certa em casos controversos? In: DWORKIN, R. Uma questão de princípio. São Paulo: Martins Fontes, 2001. cap. 5.

8. DWORKIN, R. O Império do direito. São Paulo: Martins Fontes, 1999.

9. HABERMAS, J. A inclusão do outro: estudos de teoria política. São Paulo: Loyola, 2002.

10. HABERMAS, J. Direito e democracia: entre facticidade e validade. v. II. $2^{a}$ ed. Rio de Janeiro: Tempo Brasileiro, 2003.

11. SANDEL, M. Liberalism and the limits of justice. Cambridge: Cambridge University Press, 1982a.

12. SANDEL, M. The Procedural Republic and the Unencumbered Self. In: AVIRENI, S.; DE-SHALIT, A. (Eds.). Comunitarism and Individualism. Oxford Readings in politics and government. New York: Oxford University Press, 1992b. p. 12-28.

13. URBINATI, N. Representation as Advocacy: A Study of Democratic Deliberation. Political Theory, Baltmore, v. 28, n. 6, p. 758-786, 2000.

14. URBINATI, N. O que torna a representação democrática? Lua Nova, São Paulo, n.67, 2006.

15. YOUNG, I. Inclusion and Democracy. Oxford: Oxford University Press, 2000.

16. YOUNG, I. Representação política, identidade e minorias. Lua Nova, São Paulo, n.67, p.139-190, 2006.

Recebido em: 22/01/2014

Aceite final: 18/06/2014 